\title{
Atopic Dermatitis and Excessive Daytime Sleepiness: Analysis of Data from 8362 Adult Subjects in a Sub-Saharan Africa Country
}

\author{
Eric Walter Pefura-Yone ${ }^{1,2, *}$, Adamou Dodo Balkissou ${ }^{3}$, Amadou Djenabou ${ }^{4}$, \\ Virginie Poka-Mayap ${ }^{4}$, Christopher Kuaban ${ }^{5}$ \\ ${ }^{1}$ Department of Internal Medicine, Faculty of Medicine and Biomedical Sciences, The University of Yaounde 1, Yaounde, Cameroon \\ ${ }^{2}$ Pneumology A Service, Yaounde Jamot Hospital, Yaounde, Cameroon \\ ${ }^{3}$ Faculty of Medicine and Biomedical Sciences of Garoua, University of Ngaoundéré, Garoua, Cameroon \\ ${ }^{4}$ Approved Treatment Center for HIV, Yaounde Jamot Hospital, Yaounde, Cameroon \\ ${ }^{5}$ Faculty of Health Sciences, University of Bamenda, Bambili, Cameroon
}

\section{Email address:}

Pefura2002@yahoo.fr (E. W. Pefura-Yone), dodobalkissou@gmail.com (A. D. Balkissou), djenabouamadou@yahoo.fr (A. Djenabou), pokavirginie@yahoo.fr (V. Poka-Mayap), ckuaban@yahoo.fr (C. Kuaban)

${ }^{*}$ Corresponding author

\section{To cite this article:}

Eric Walter Pefura-Yone, Adamou Dodo Balkissou, Amadou Djenabou, Virginie Poka-Mayap, Christopher Kuaban. Atopic Dermatitis and Excessive Daytime Sleepiness: Analysis of Data from 8362 Adult Subjects in a Sub-Saharan Africa Country. American Journal of Internal Medicine. Vol. 7, No. 5, 2019, pp. 127-131. doi: 10.11648/j.ajim.20190705.14

Received: September 8, 2019; Accepted: September 26, 2019; Published: October 11, 2019

\begin{abstract}
Sleep disorders in patients with atopic dermatitis (AD) are common and can have a negative impact on the quality of life of the affected subjects. Very little data are available on the association between AD and excessive daytime sleepiness (EDS) in adults. The objective of this study was to compare the prevalence of EDS in subjects with AD and those without AD, and to investigate the determinants of EDS in adults with AD. In this cross-sectional population-based study conducted from 2015 to 2018 in Cameroon, adult subjects aged at least 19 years were included by multi-level stratified random sampling. AD was defined as the presence of a chronic itchy dermatitis evolving intermittently over a period of at least 6 months and electively affecting certain areas (fronts of the elbows, back of the knees, front of the ankles, under the buttocks, around the neck, around the eyes or ears) during the last 12 months preceding the survey. EDS was defined by an Epworth score $\geq 10$. Logistic regression was used to investigate the independent association between EDS and AD. A difference was considered significant if $\mathrm{p}<0.05$. A total of 8362 subjects (55.2\% women) with median age $\left(25^{\text {th }}-75^{\text {th }}\right.$ percentiles) of 39 (27-54) years were included. There were 217 subjects $(2.6 \%)$ with $\mathrm{AD}$ and 1022 subjects $(12.2 \%)$ with EDS. The prevalence of EDS was higher in subjects with $\mathrm{AD}$ than in those without $\mathrm{AD}(22.1 \%$ vs. $12 \%, \mathrm{p}<0.001)$. In multivariate analysis integrating potential confounders (area of recruitment, age, education level, body mass index, association with other allergic diseases), AD remained independently associated with EDS with an adjusted odds ratio (95\% CI) of 2.18 (1.54-3.08). No independent associated factors to EDS were found in subjects with AD. There is an independent association between EDS and AD, and nearly one quarter of patients with AD has EDS in this setting. It is necessary to consider the systematic evaluation of EDS in subjects with $\mathrm{AD}$ to optimize their management.
\end{abstract}

Keywords: Atopic Eczema, Dermatitis, Daytime Sleepiness, Sleep Disorders, Africa

\section{Introduction}

Atopic dermatitis $(\mathrm{AD})$ is one of the most common allergic diseases, affecting up to $14 \%$ of adults in industrialized countries according to recent studies $[1,2]$. AD is a chronic inflammatory disease characterized by intense pruritus and a negative impact on the quality of life of subjects suffering from this condition [3]. Sleep disorders are common in adults 
with AD [4]. The main sleep disorders observed during AD are insomnia, difficulty falling asleep, night awakenings and early awakenings and non-restorative sleep [4]. Excessive daytime sleepiness (EDS) is a major consequence of sleep disturbances that may be responsible for a decrease in quality of life and in driving or workplace accidents $[5,6]$. In studies of sleep disorders and atopic dermatitis, very few studies have examined EDS in adults. In the recent systematic review done by Jeon et al. the specific evaluation of EDS was not found in most of the 39 included studies [4]. Moreover, we did not find any study done in Africa on the association of $\mathrm{AD}$ and EDS. Thus, the objective of this study was to compare the prevalence of EDS in subjects with $\mathrm{AD}$ and those without $\mathrm{AD}$, and to investigate for factors associated to EDS in $\mathrm{AD}$ subjects in the general adult population in Cameroon.

\section{Methods}

\subsection{Setting and Participants}

Participant's data included in three cross-sectional surveys conducted from 2015 to 2018 as part of Cameroon's respiratory health surveys were used in this study. The first survey was carried out in the health district of Bandjoun (semi-urban and rural areas with Cameroonian equatorial climate) from November 2015 to April 2016 (6 months), the second study was carried out in the city of Douala (urban area with Cameroonian equatorial climate) from November 2016 to April 2017 (6 months), and the third one carried out in Garoua (urban area with Sudano-Sahelian climate) and Figuil (semi-urban area with Sudano-Sahelian climate) from December 2017 to April 2018 (5 months). Subjects aged 19 years and above who gave informed consent to participate in the study were included. All surveys were approved by the Institutional Ethics Committee of the Faculty of Medicine and Pharmaceutical Sciences of the University of Douala, Cameroon.

\subsection{Sampling}

The same sampling method was used in the three surveys and published elsewhere [7]. In summary, a three-level stratified sampling method was applied in each recruitment area. At the $1^{\text {st }}$ level, the enumeration areas corresponding to those used for the national immunization days were selected by simple random sampling. At the second level, households were selected by systematic sampling with variable sampling rate according to the size of each enumeration area. Subjects aged at least 19 years living in households selected at the $2^{\text {nd }}$ level were then invited to participate in the study.

\subsection{Data Collection}

The data were collected by the final year medical students. The three databases were associated and the variables of interest extracted. Socio-demographic data including age, sex, level of formal education and marital status were noted. Smoking habits were identified and subjects classified as: smoker (a subject who reported having smoked at least one cigarette a day for at least one year or who had smoked at least 20 packs of cigarettes in his life and who continues to smoke), ex-smoker (anyone who reported stopping smoking for at least 6 months) and non-smoker. Alcohol consumption was classified as regular current consumption, occasional consumption, former consumption an non-consumption [8]. Weight $(\mathrm{kg})$ and height $(\mathrm{m})$ were used to calculate the body mass index (BMI) as the ratio of weight $(\mathrm{kg})$ to the square of height $(\mathrm{m})$. The different categories of body mass index (BMI) are those used internationally and include: $\mathrm{BMI}<18.5 \mathrm{~kg} / \mathrm{m}^{2}$ (undernutrition), BMI of 18.5 to $24.9 \mathrm{~kg} / \mathrm{m}^{2}$ (normal), BMI of 25 to $29.9 \mathrm{~kg} / \mathrm{m}^{2}$ (overweight) and $\mathrm{BMI} \geq 30 \mathrm{~kg} / \mathrm{m}^{2}$ (obesity).

Clinical data to define $\mathrm{AD}$ and other allergic diseases were identified [9, 10]. Regarding $\mathrm{AD}$, the following information was noted: rash affecting the fronts of the elbows, back of the knees, front of the ankles, the under of the buttocks, parts around the neck, the eyes or ears and pruritus that appear and disappear intermittently over a period of at least 6 months in the last 12 months. AD has been defined as the existence of a chronic itchy dermatitis evolving intermittently over a period of at least 6 months and electively affecting certain areas (fronts of the elbows, behind the knees, in front of the ankles, under the buttocks, around the neck, around the eyes or ears) during the last 12 months preceding the survey. The frequency of sleep disorders and $\mathrm{AD}$ was noted, and classified as mild (absence of pruritus-induced sleep disturbances) or moderate to severe (presence of pruritusinduced sleep disorders). Data on rhinitis (sneezing, runny nose or nasal obstruction without colds or flu) in the last 12 months and allergic rhinitis (signs of rhinitis accompanied by tearing and itchy eyes) in the last 12 months were also recorded. The existence or absence of wheezing was extracted. Daytime sleepiness was assessed by the Epworth scale [11]. EDS was defined by an Epworth score $\geq 10$ [12].

\subsection{Data Analysis}

Our data were analyzed using IBM-SPSS 20 for Windows (IBM, Chicago, USA). Qualitative data were summarized in terms of proportions and frequency. Quantitative variables were described by their mean (standard deviation) or median $\left(25^{\text {th }}-75^{\text {th }}\right.$ percentiles). The Chi-2 test was used for the comparison of proportions. Quantitative variables were compared using the non-parametric Mann-Whitney U test. Logistic regression was used to investigate the factors associated with EDS. The factors associated with EDS in univariate analysis with $\mathrm{p}<0.10$ were introduced into the same multinomial logistic regression model to search for independent factors associated with EDS. A difference was considered significant if $\mathrm{p}<0.05$.

\section{Results}

\subsection{General Characteristics of Study Population}

Of the 8415 respondents, 53 subjects had missing data on 
EDS or $\mathrm{AD}$ and were excluded from the analysis. The characteristics of the 8362 participants definitively included are presented in Table 1 . Nearly $70 \%$ of the subjects included were found in the Equatorial area (Bandjoun and Douala) and $30 \%$ in the Sahelian area (Garoua and Figuil). There were $4620(55.2 \%)$ women and $3742(44.8 \%)$ men. The median age (25th-75th percentiles) of our participants was 39 (27-54) years and $22.1 \%$ of subjects were obese. The prevalence of $\mathrm{AD}$ was $2.6 \%$ and that of EDS was $12.2 \%$.

Table 1. General characteristics of study population.

\begin{tabular}{|c|c|}
\hline Characteristics & $\mathrm{N}=8362(\%)$ \\
\hline \multicolumn{2}{|l|}{ Area of recruitment } \\
\hline Bandjoun & $3032(36.3)$ \\
\hline Douala & $2727(32.6)$ \\
\hline Garoua & $1652(19.8)$ \\
\hline Figuil & $951(11.4)$ \\
\hline \multicolumn{2}{|l|}{ Gender } \\
\hline Female & $4620(55.2)$ \\
\hline Male & $3742(44.8)$ \\
\hline \multicolumn{2}{|l|}{ Age } \\
\hline Mean (SD) & $41.9(16.9)$ \\
\hline Median $\left(25^{\text {th }}-75^{\text {th }}\right.$ percentiles $)$ & $39(27-54)$ \\
\hline \multicolumn{2}{|l|}{ Educational level } \\
\hline None & $1818 / 8361(21.7)$ \\
\hline Primary & $1960 / 8361(23.4)$ \\
\hline Secondary & $3132 / 8361(37.5)$ \\
\hline University & $1451 / 8361(17.4)$ \\
\hline \multicolumn{2}{|l|}{ Marital status } \\
\hline In couple & $4644 / 8348(55.6)$ \\
\hline Not in couple & $3704 / 8348(44.4)$ \\
\hline \multicolumn{2}{|l|}{ Smoking habits } \\
\hline Non-smokers & $7240 / 8354(86.7)$ \\
\hline Former smokers & $527 / 8354(6.3)$ \\
\hline Non-smoker & $587 / 8024(7)$ \\
\hline \multicolumn{2}{|l|}{ Alcohol consumption } \\
\hline Regular & $821 / 5755(14.3)$ \\
\hline Occasional & $3869 / 5755(67.2)$ \\
\hline Former & $328 / 5755(5.7)$ \\
\hline Non-drinker & $737 / 5755(12.8)$ \\
\hline \multicolumn{2}{|l|}{ BMI. $\mathrm{Kg} / \mathrm{m}^{2}$} \\
\hline Mean (SD) & $26.2(5.7)$ \\
\hline Median $\left(25^{\text {th }}-75^{\text {th }}\right.$ percentiles $)$ & $25.2(22.1-29.3)$ \\
\hline \multicolumn{2}{|l|}{ BMI categories } \\
\hline Normal & $3711 / 8316(44.6)$ \\
\hline Under nutrition & $319 / 8316(3.8)$ \\
\hline Overweight & $2451 / 8316(29.5)$ \\
\hline Obesity & $1835 / 8316(22.1)$ \\
\hline Wheezing & $248 / 8360(3)$ \\
\hline Allergic rhinitis & $255 / 8354(3.1)$ \\
\hline Atopic dermatitis & $217(2.6)$ \\
\hline Excessive daytime sleepiness & $1022(12.2)$ \\
\hline
\end{tabular}

$\mathrm{SD}$, standard deviation; BMI, body mass index.

\subsection{Association Between Excessive Daytime Sleepiness and Atopic Dermatitis}

The prevalence of EDS was $22.1 \%$ in subjects with $\mathrm{AD}$ and $12 \%$ in subjects without $\mathrm{AD}$, corresponding to an unadjusted odds ratio $(95 \% \mathrm{CI})$ of $2.09 \quad(1.51-2.90), \quad \mathrm{p}<0.001$. In multivariate analysis taking into account potential confounding factors (age, sex, education level, marital status, body mass index, wheezing in the past 12 months, allergic rhinitis), EDS was associated to $\mathrm{AD}$ with an adjusted odds ratio $(95 \% \mathrm{CI})$ of
2.18 (1.54-3.08), $\mathrm{p}<0.001$. The multivariate analysis of association between EDS and AD is summarized in the Table 2.

Table 2. Multivariate analysis of association between excessive daytime sleepiness and atopic dermatitis.

\begin{tabular}{lll}
\hline Factors & AOR (IC à 95\%) & p \\
\hline Atopic dermatitis & $2.18(1.54-3.08)$ & $<0.001$ \\
Area of recruitment & & \\
Sahelian area & 1 & \\
Equatorial area & $1.91(1.55-2.35)$ & $<0.001$ \\
Gender & & \\
Female & 1 & \\
Male & $1.22(1.06-1.41)$ & 0.007 \\
Age, per 1 year increase & $1.00(0.99-1.01)$ & 0.402 \\
Educational level & & \\
University & 1 & \\
None & $1.09(0.79-1.50)$ & 0.614 \\
Primary & $1.50(1.18-1.92)$ & 0.001 \\
Secondary & $1.56(1.27-1.91)$ & $<0.001$ \\
Marital status & & \\
In couple & 1 & \\
Not in couple & $0.96(0.83-1.11)$ & 0.570 \\
BMI, per 1kg/m ${ }^{2}$ increase & $1.04(1.03-1.05)$ & $<0.001$ \\
Wheezing & $1.13(0.77-1.65)$ & 0.534 \\
Allergic rhinitis & $1.53(1.09-2.17)$ & 0.015 \\
\hline
\end{tabular}

AOR, adjusted odds ratio; BMI, body mass index.

\subsection{Determinants of Excessive Daytime Sleepiness in Subjects with Atopic Dermatitis}

Univariate analysis of the potential factors associated with EDS in participants with AD are presented in Table 3. Factors associated with EDS in univariate analysis in subjects with $\mathrm{AD}(\mathrm{p}<0.10)$ were age, moderate to severe $\mathrm{AD}$, body mass index, and allergic rhinitis.

Table 3. Univariate analysis of factors associated to excessive daytime sleepiness (EDS) in subjects with atopic dermatitis (AD).

\begin{tabular}{|c|c|c|c|}
\hline Factors & $\operatorname{EDS} N=48(\%)$ & $\begin{array}{l}\text { Absence of EDS } \\
\mathrm{N}=169(\%)\end{array}$ & $\mathbf{p}$ \\
\hline \multicolumn{4}{|l|}{ Area of recruitment } \\
\hline Equatorial area & $22(45.8)$ & $97(57.4)$ & 0.155 \\
\hline Sahelian area & $26(54.2)$ & $72(42.6)$ & \\
\hline \multicolumn{4}{|l|}{ Gender } \\
\hline Male & $28(58.3)$ & $85(50.3)$ & 0.325 \\
\hline Female & $20(41.7)$ & $84(49.7)$ & \\
\hline Age, years, mean (SD) & $42.5(17.9)$ & $37.6(16.0)$ & 0.059 \\
\hline \multicolumn{4}{|l|}{ Educational level } \\
\hline None & $16(33.3)$ & $33(19.5)$ & 0.246 \\
\hline Primary & $8(16.7)$ & $33(19.5)$ & \\
\hline Secondary & $17(35.4)$ & $70(41.4)$ & \\
\hline University & $7(14.6)$ & $33(19.5)$ & \\
\hline \multicolumn{4}{|l|}{ Severity of AD } \\
\hline Mild & $13 / 36(63.9)$ & $66 / 125(52.8)$ & 0.078 \\
\hline Moderate/severe & $23 / 36(22.4)$ & $59 / 125(47.2)$ & \\
\hline $\begin{array}{l}\text { BMI, } \mathrm{kg} / \mathrm{m}^{2} \text {, Mean } \\
\text { (SD) }\end{array}$ & $27.2(6.8)$ & $25.3(6.0)$ & 0.090 \\
\hline \multicolumn{4}{|l|}{ Wheezing } \\
\hline Yes & $8(16.7)$ & $16(9.5)$ & 0.160 \\
\hline No & $40(83.3)$ & $153(90.5)$ & \\
\hline \multicolumn{4}{|l|}{ Allergic rhinitis } \\
\hline Yes & $10(20.8)$ & $19(11.2)$ & 0.085 \\
\hline No & $38(79.2)$ & $150(88.8)$ & \\
\hline
\end{tabular}

SD, standard déviation. 
In multivariate analysis we did not find any independent factors associated to EDS in subjects with AD (Table 4).

Table 4. Multivariate analysis of factors associated with excessive daytime sleepiness (EDS) in subjects with atopic dermatitis (AD).

\begin{tabular}{lll}
\hline Factors & AOR $(\mathbf{9 5 \%}$ CI) & p \\
\hline Age, per 1 year increase & $1.02(0.99-1.05)$ & 0.069 \\
Moderate/severe AD & $1.63(0.74-3.61)$ & 0.227 \\
BMI, per 1kg/m ${ }^{2}$ increase & $1.04(0.98-1.10)$ & 0.135 \\
Allergic rhinitis & $1.22(0.43-3.48)$ & 0.714 \\
\hline
\end{tabular}

\section{Discussion}

The main findings from this large study conducted in four Cameroonian areas are: 1) the prevalence of EDS was higher in subjects with $\mathrm{AD}$ compared to subjects without this condition 2) there was an independent association between EDS and $\mathrm{AD} 3$ ) No associated independent factors of EDS were found in subjects with AD.

Very few studies have been done on the association between $\mathrm{EDS}$ and $\mathrm{AD}$ in adults. In a recent systematic review, Jeon et al. identified 39 studies of sleep disorders in adults with $\mathrm{AD}$ [4]. In this review, very few studies focused on EDS, yet EDS is a consequence of most sleep disorders and especially leads to a significant loss of quality of life [13]. In our study, subjects with $\mathrm{AD}$ were 2.09 times more likely to have EDS compared to subjects without AD. These results corroborate the results of a large US study of nearly 35,000 subjects. In the latter study, the prevalence of EDS was $26 \%$ and $11.7 \%$, in subjects with and without AD respectively, corresponding to a 2.04-fold increase in risk in subjects with $\mathrm{AD}[13]$.

In another study by Li et al. including 287 patients aged 18 to 69 years with $\mathrm{AD}, 13 \%$ of patients reported significant sleepiness in the day [14]. Prevalent EDS in subjects with $\mathrm{AD}$ can be explained by sleep disorders associated with $\mathrm{AD}$ and by the other mechanisms including circadian rhythm disturbances related to cytokines produced during this chronic inflammatory condition. Nocturnal sleep disturbances are common during AD. These sleep disorders include insomnia, impaired sleep duration and sleep fragmentation [4]. In our study, moderate to severe sleep disturbances were more common in atopic subjects with EDS with borderline $p$-value $(p=0.078)$. This can be explained by the limited size of sub-sample of patients with AD. In addition, other mechanisms causing EDS can be discussed in these subjects. For example, Gupta et al. have shown that some atopic patients have an impairment in circadian rhythm associated with pruritus while other patients show a nocturnal increase in transcutaneous fluid loss, thus altering the secretion of cortisol [15]. Moreover, there is an overproduction of inflammatory cytokines associated with sleep regulation during allergic diseases [16]. All of these mechanisms explain the complex relationship between EDS, sleep disorders and AD.

We did not find any factors associated with EDS in subjects with $\mathrm{AD}$ in particular no association with moderate to severe sleep disorders or other allergic diseases (asthma and allergic rhinitis symptoms). In the study by Li et al., the severity of $\mathrm{AD}$ is associated with an increase in nocturnal sleep disturbances and the severity of daytime sleepiness [14]. In our univariate analysis, the nocturnal sleep disturbances were slightly more frequent in patient with AD and EDS, but this association was no longer found after multivariate analysis. Also, in a Japanese study of 112 adult subjects, a low to moderate correlation was found between the severity of AD measured by Severity Scoring of Atopic Dermatitis (SCORAD) index [17] and sleep disorders assessed by Pittsburgh Sleep Quality Index [18]. Silverberg at al. found an association between sleep disorders in subjects with $\mathrm{AD}$ and other allergic diseases, female sex, older age and low income [13]. In our study, the association between allergic rhinitis and EDS in subjects with $\mathrm{AD}$ was borderline in univariate analysis but was not in the multivariate analysis after including other confounding factors. The association between obesity and EDS in subjects with AD was not found in our study as reported in the study Li et al. [14]. However, in the general population EDS is associated to BMI irrespectively of other comorbidities as also shown in this study $[19,20]$.

The main limitation of this study is its cross-sectional nature which does not allow determining the direction of the occurrence of AD and EDS. Other limitations include the use of the Epworth scale (subjective scale) for the evaluation of EDS and the epidemiological definition of AD. The psychometric validity of the Epworth scale has recently been shown in the African population [21]. Nevertheless, this study is one of the first in Africa on the relationship between $\mathrm{AD}$ and EDS. The other strengths of the study are the analysis of over 8000 subjects and the inclusion of other allergic diseases among the confounders in the multivariate analysis.

\section{Conclusion}

In this population-based study in a sub-Saharan African country, excessive daytime sleepiness is independently associated with atopic dermatitis. Excessive daytime sleepiness is two-times more frequent in subjects with atopic dermatitis in comparison to those without atopic dermatitis and nearly one quarter of adults with atopic dermatitis have excessive daytime sleepiness. There are no associated factors to excessive daytime sleepiness in subjects with atopic dermatitis. Specifically, there is no association between the presence of sleep disturbances at night and excessive daytime sleepiness. The evaluation of daytime sleepiness should be routinely performed in patients with atopic dermatitis as well as the evaluation of the other components of sleep disorders.

\section{References}

[1] Chiesa Fuxench ZC, Block JK, Boguniewicz M, et al. Atopic Dermatitis in America Study: A Cross-Sectional Study Examining the Prevalence and Disease Burden of Atopic Dermatitis in the US Adult Population. J Invest Dermatol 2019; 139: 583-90. doi: 10.1016/j.jid.2018.08.028. 
[2] Theodosiou G, Montgomery S, Metsini A, et al. Burden of Atopic Dermatitis in Swedish Adults: A Population-based Study. Acta Derm Venereol Published Online First: 2019. doi: $10.2340 / 00015555-3257$.

[3] Drucker AM, Wang AR, Li W-Q, et al. The Burden of Atopic Dermatitis: Summary of a Report for the National Eczema Association. J Invest Dermatol 2017; 137: 26-30. doi: 10.1016/j.jid.2016.07.012.

[4] Jeon C, Yan D, Nakamura M, et al. Frequency and Management of Sleep Disturbance in Adults with Atopic Dermatitis: A Systematic Review. Dermatol Ther (Heidelb) 2017; 7: 349-64. doi: 10.1007/s13555-017-0192-3.

[5] Sagaspe P, Taillard J, Bayon V, et al. Sleepiness, near-misses and driving accidents among a representative population of French drivers. J Sleep Res 2010; 19: 578-84. doi: 10.1111/j.1365-2869.2009.00818.x.

[6] Garbarino S, Guglielmi O, Sanna A, et al. Risk of Occupational Accidents in Workers with Obstructive Sleep Apnea: Systematic Review and Meta-analysis. Sleep 2016; 39: 1211-8. doi: 10.5665/sleep.5834.

[7] Pefura-Yone EW, Kengne AP, Balkissou AD, et al. Prevalence of Asthma and Allergic Rhinitis among Adults in Yaounde, Cameroon. PLoS One 2015; 10: e0123099. doi: 10.1371/journal.pone.0123099.

[8] Lydia Gisle SD. Enquête de santé 2013. rapport 2: comportement de santé et style de vie. https:/his.wivisp.be/fr/Documents partages/AL_FR_2013.pdf.

[9] Asher MI, Keil U, Anderson HR, et al. International Study of Asthma and Allergies in Childhood (ISAAC): rationale and methods. Eur Respir J 1995; 8: 483-91. doi: 10.1183/09031936.95.08030483.

[10] Burney PG, Luczynska C, Chinn S, et al. The European Community Respiratory Health Survey. Eur Respir J 1994; 7: 954-60. http://www.ncbi.nlm.nih.gov/pubmed/8050554 (accessed 22 Mar2015).

[11] Johns MW. A new method for measuring daytime sleepiness: the Epworth sleepiness scale. Sleep 1991; 14: 540-5. doi: 10.1093/sleep/14.6.540.

[12] Doneh B. Epworth Sleepiness Scale. Occup Med (Lond) 2015; 65: 508. doi: 10.1093/occmed/kqv042.
[13] Silverberg JI, Garg NK, Paller AS, et al. Sleep disturbances in adults with eczema are associated with impaired overall health: a US population-based study. J Invest Dermatol 2015; 135: 56-66. doi: 10.1038/jid.2014.325.

[14] Li JC, Fishbein A, Singam V, et al. Sleep Disturbance and Sleep-Related Impairment in Adults with Atopic Dermatitis: A Cross-sectional Study. Dermat contact, atopic, Occup drug; 29: 270-7. doi: 10.1097/DER.0000000000000401.

[15] Gupta MA, Gupta AK. Sleep-wake disorders and dermatology. Clin Dermatol; 31: 118-26. doi: 10.1016/j.clindermatol.2011.11.016.

[16] Chang Y-S, Chiang B-L. Mechanism of Sleep Disturbance in Children with Atopic Dermatitis and the Role of the Circadian Rhythm and Melatonin. Int J Mol Sci 2016; 17: 462. doi: 10.3390/ijms 17040462 .

[17] Severity scoring of atopic dermatitis: the SCORAD index. Consensus Report of the European Task Force on Atopic Dermatitis. Dermatology 1993; 186: 23-31. doi: $10.1159 / 000247298$.

[18] Yano C, Saeki H, Ishiji T, et al. Impact of disease severity on sleep quality in Japanese patients with atopic dermatitis. J Dermatol Sci 2013; 72: 195-7. doi: 10.1016/j.jdermsci.2013.06.010.

[19] Maugeri A, Medina-Inojosa JR, Kunzova S, et al. Sleep Duration and Excessive Daytime Sleepiness Are Associated with Obesity Independent of Diet and Physical Activity. Nutrients 2018; 10. doi: 10.3390/nu10091219.

[20] Lee Y, Kanagasabai T, Rigobon A V, et al. Depressive symptom severity mediates the association between sleep disturbance and obesity in US adults: Results from the NHANES. Ann Clin Psychiatry 2019; 31: 111-22. http://www.ncbi.nlm.nih.gov/pubmed/31046032.

[21] Manzar MD, Salahuddin M, Alamri M, et al. Psychometric properties of the Epworth sleepiness scale in Ethiopian university students. Health Qual Life Outcomes 2019; 17: 30. doi: 10.1186/s12955-019-1098-9. 